\title{
SUS e as Teias de Diálogos (im)pertinentes para transformar a formação dos trabalhadores de saúde com vistas à humanização das práticas
}

SUS and the webs of pertinent and irrelevant dialogue for transforming

the training of healthcare workers with a view to humanization of practices

SUS y las tramas de diálogos (im)pertinentes para transformar

la formación de los trabajadores de salud con miras en la humanización de las prácticas

Rita de Cássia Duarte Lima

É um prazer e privilégio o convite dos editores da revista Interface para debater o texto provocativo de Mattos (2009), implicando-nos na sua posição ético/política de que vale a pena continuar lutando pela agenda da Reforma Sanitária Brasileira.

Ruben aponta diferentes vertentes produtoras dos processos históricos que forjaram a época, os ideais do Sistema Único de Saúde (SUS), aglutinando forças em defesa de uma sociedade democrática e igualitária. Ele desmistifica linearidades que levam, muitas vezes, à falsa impressão de homogeneidade e consensos do movimento. Ao contrário, chama atenção para a heterogeneidade e tensões no seu interior, permitindo que muitas das aspirações não fossem incorporadas e reconhecidas na institucionalidade do SUS.

Ao propor discutir os princípios do SUS e as tramas da humanização, revela avanços, mas também tece redes que se entrelaçam nas práticas, ao desconsiderar muitas das dimensões de sofrimento, autonomia e emancipação do usuário. Isso contribui para que ocorram redes de maus encontros, decorrentes dos vários

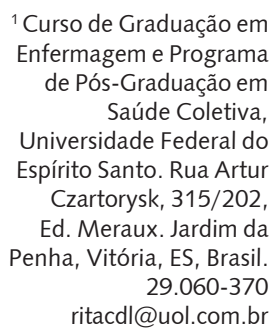

${ }^{1}$ Curso de Graduação em Enfermagem e Programa de Pós-Graduação em Saúde Coletiva, Universidade Federal do Espírito Santo. Rua Artur Czartorysk, 315/202, Ed. Meraux. Jardim da Penha, Vitória, ES, Brasil. 29.060-370 ritacdl@uol.com.br 
olhares produzidos pelas formas de organizar os serviços: sem escuta qualificada, acolhimento, vínculos de várias ordens e sem atentar-se para causas e consequências das humilhantes filas para acessar serviços de saúde, independente do nível de complexidade demandado (Schwartz, Lima, 2008).

O seu alerta à transformação e consequente humanização das práticas de saúde nos remete a momentos anteriores que antecedem os atos profissionais, como o esvaziamento do tema da formação no SUS, uma vez que impacta os demais processos. Desafia-nos a refletir sobre até que ponto o distanciamento e resistências dos trabalhadores não são gestados e reproduzidos de início nos diversos e complexos cenários da formação - tema que desenvolverei a seguir.

O próprio Mattos (2008) aponta os limites da formação para dar conta das diversidades que compõem o SUS, pela pouca potência para transformar os modelos hegemônicos, muito mais vinculados a interesses outros - como os das corporações profissionais, da indústria de equipamentos médicos e farmacêuticos - do que às necessidades dos usuários.

Nossa experiência com alunos ingressantes na Graduação em Enfermagem na UFES nos permite apreender a dimensão dos desafios que ainda temos de enfrentar. Identificamos que os principais motivos que levam alunos a buscarem cursos na área de saúde são "cuidar das doenças dos órgãos e de pessoas fragilizadas sofrendo com alguma doença".

Manifestam desejo de não serem usuários desses serviços e consideram que o SUS é para quem precisa, é pobre e excluído de várias políticas públicas e privadas. O que mais os estimulam é fazer a "disciplina anatomia", pela possibilidade de conhecerem as peças, os órgãos que compuseram um dia um corpo, um ser humano. Nesse momento, estão interessados nas partes, a referência é a doença e o olhar é ainda distante do doente (sujeito), recorte que poderá ou não ser resgatado ao longo de suas trajetórias, seja como estudantes seja como trabalhadores de saúde (Lima et al., 2009).

Essas motivações-, partindo da permissão e da legitimidade para tocar, curar e cuidar do corpo, foram e têm sido os principais motivos a guiar as práticas de formação e, posteriormente, a profissional, com implicações futuras na organização do processo de trabalho, podendo, conforme as escolhas, produzir potência ou banalização da vida, do cuidado e da morte.

Tais constatações nos obrigam a olhar como vem se institucionalizando esse processo, uma vez que a experiência primeira desses alunos se dá, majoritariamente, na ausência do cuidado. Invariavelmente, estabelecem-se a partir do silêncio da morte, num corpo fragmentado em peças, pedaços amorfos e anônimos.

A formação tem se produzido com baixa capacidade crítica e associação com os fatores que determinam os lugares sociais, num mundo de tantas desigualdades e iniquidades no acesso e na utilização dos equipamentos públicos.

Passados vinte anos da institucionalização do SUS, estamos diante dos muitos desafios para ressignificar os processos de formação e de trabalho, articulando sua relação não só com a ciência, a técnica, a doença, o sofrimento e a morte, mas também com: a saúde, a vida, a alegria, a felicidade e o prazer, o conhecimento, o afeto e a produção do cuidado fomentador de cidadania, a solidariedade e a inclusão dos atores envolvidos.

A exemplo de outras experiências de formação e da gestão do trabalho em saúde, o cuidado ao doente e ao sofrimento causado pela doença se revelou como o grande mobilizador nas escolhas desses alunos, ratificando a imagem social e cultural de que ser profissional de saúde é, antes de tudo, ser um cuidador de doenças, e não da promoção da saúde de pessoas com necessidades distintas, que nem sempre estão relacionadas à doença e ao sofrimento dela decorrente.

Para Merhy et al. (2003), o cenário dos serviços de saúde é espaço de produção, tanto das relações quanto dos bens e produtos. Eles nos interrogam sobre sentidos e significados do trabalho em saúde, pois qualquer que seja nossa abordagem junto ao usuário, a relação que se estabelecerá será sempre a de uma pessoa atuando sobre a outra, havendo, nesse processo, trocas, jogos de expectativas, momentos de fala, escutas e interpretações. Há ou não a produção de uma acolhida das intenções que as pessoas depositam neste encontro.

Posto isso, se somos moldados por processos de formação centrados em órgãos, como nos advertem Lima (2009) e Mattos (2008), reproduzimos esses fragmentos, contribuindo para o assujeitamento das pessoas, fragilizando-se suas necessidades, e produzimos como modelo o descuidado. Ao segmentar o 
ato de cuidar em órgãos doentes, perde-se o sentido da integralidade e fortalece-se a desintegração do homem, conforme é visto no processo de formação em várias "disciplinas dos currículos". Perdem-se muitas das dimensões cuidadoras na perspectiva dada por Santos-Filho e Barros (2007).

Cuidar do outro ganha sentido quando a existência do outro torna-se significativa, independente do papel social e da pessoa a ser cuidada. É o sentimento de importância, a solidariedade com o sofrimento que nos levam a nos dedicarmos ao outro e a nós mesmos, permitindo participarmos de suas buscas, seus sofrimentos, fracassos, limitações e, também, dos seus afetos, sucessos e avanços, e reconhecermos nossos limites e possibilidades nos encontros que produzem vida/cuidado/sofrimento/ morte.

O texto do Ruben nos convoca a compromissos éticos/políticos que incorporam estratégias de transformação, com vistas a qualificar e humanizar as práticas de saúde, nelas inclusas a formação, tornando provocador, inadiável e essencial o debate sobre o sofrimento no cuidado para a promoção e a qualidade da vida.

Assim, toma, como pressuposto inegociável, a construção de um SUS humanizado que seja objeto de desejo, responsabilidade, compromisso e uso consciente da sociedade, inclusive dos estudantes, docentes e demais trabalhadores de saúde, entrando numa luta, como afirma o autor, que vale a pena travar em direção à defesa da vida e da cidadania da/e na sociedade brasileira.

\section{Referências}

LIMA, R.C.D. et al. Significando os sentidos da vida na formação dos profissionais de saúde: com a palavra os estudantes de enfermagem da Universidade Federal do Espírito Santo. Cogitare Enferm., 2009. No prelo.

MATTOS, R.A. Princípios do Sistema Único de Saúde (SUS) e a humanização das práticas de saúde. Interface - Comunic., Saude, Educ., p.771-80, 2009.

Integralidade, trabalho, saúde e formação profissional: algumas reflexões

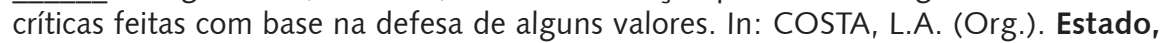
sociedade e formação profissional em saúde: contradições e desafios em 20 anos do SUS. Rio de Janeiro: Fiocruz, 2008. p.313-52.

MERHY, E.E. et al. O trabalho em saúde: olhando e experenciando o SUS no cotidiano. São Paulo: Hucitec, 2003.

SANTOS-FILHO, S.; BARROS, M.E.B. Trabalhador da saúde: muito prazer! Protagonismo dos trabalhadores na gestão do trabalho em saúde. Ijui: Editora Ijui, 2007.

SCHWARTZ, T.D.; LIMA, R.C.D. Estratégia Saúde da Família: avaliando o acesso ao SUS a partir da percepção dos usuários da unidade de saúde de resistência, na Região de São Pedro, no Município de Vitória/ES. Cienc. Saude Colet., 2008. Disponível em: <http://www. cienciaesaudecoletiva.com.br>. Acesso em: 12 fev. 2009. 